\title{
The significance of relative density for particle damage in loaded and sheared gravels
}

\author{
Stephen Fityus ${ }^{1}$ and Emöke Imre ${ }^{2}$ \\ ${ }^{1}$ The School of Engineering, University of Newcastle, University Drive, Callaghan, Australia, 2308. \\ ${ }^{2}$ Kandó Kálmán Electrical Engineering Faculty, Obuda University BMF, Bp., Hungary
}

\begin{abstract}
For granular assemblages of strong particles, an increase in the relative density usually leads to a significant increase in shear strength, which is evident as a peak strength, accompanied by significant dilation as the peak strength is attained. This paper describes an experimental study of shearing in assemblages of weak particles, where particle breakage offsets dilation for all but the lowest of confining stresses. In such materials, prone to particle breakage, the shear strengths of loose and dense assemblages rapidly converge to similar values as confining stress increases, and any benefit of greater relative density is lost. This is attributed to the densification effect associated with the loading under a high stress prior to shearing, which is characterised by widespread particle breakage and the formation of smaller particles to occupy space between coarser ones. Interestingly, under both low and high stresses, there was a tendency for greater particle breakage in the loose samples, as a result of both shearing and compression. This result suggests that, despite the denser assemblage having its particles more rigidly constrained and less able to rearrange to avoid direct loading, the influence of greater load-spreading capacity afforded by an increased number of particle contacts in a denser sample, is more dominant in controlling breakage.
\end{abstract}

\section{Introduction}

In Geomechanics, the shearing of granular materials is usually studied in the context of soils in which the particles are small and strong relative to the stresses they are likely to encounter under working conditions [1-3].

Rocky materials (waste rock and rock fills) have received considerably less attention. It is generally considered that the strength of smaller particles is greater than the strength of larger particles of the same material, since the likelihood of larger particles containing flaws is inherently greater $[4,5]$. Furthermore, structures composed of rock fill (waste rock dumps and rockfill dams) are typically large or very large [6], so the likelihood of particle breakage/crushing is much greater. Hence, the significance of breakage for the behaviour of coarse materials is potentially greater.

It is well understood that breakage in granular materials is related to the particular granular mechanisms which are active during shearing, such as particle rubbing, sliding and rolling, or particle breakage, which may involve comminution of thin corners/edges or complete particle failure [7]. Generally, rubbing, sliding and rolling dominate under lower stresses, whereas breakage will become more prevalent as the applied stresses increase and dilation is suppressed [8]. As a result, it is generally believed that the shear strength envelope is non-linear $[9,10]$.

Shearing mechanisms and non-linear shear strength envelopes have been linked through the phenomenon of dilation, (sample expansion during shear). The influence of the stress environment (confinement) on dilation has been well studied $[1,7]$, but the transition from dilation and particle sliding to compression and grain crushing is also affected by the relative density of the granular assemblage, and this has received considerably less attention.

In this paper, the significance of relative density for the dilation response of sheared gravels, and its consequences for the onset and extent of particle breakage are considered.

\section{Methods}

The material used in this study was mine waste consisting primarily of a siltstone which was obtained from Rolleston Coal mine in the Bowen Basin in Australia. The unconfined compressive strength (UCS) of rocks from which the sample was derived was of the order of $5 \mathrm{MPa}$.

* Corresponding author: stephen.fityus@newcastle.edu.au 
For the purposes of this study, the samples were prepared so that all particles were larger than $4.75 \mathrm{~mm}$, and particle damage was characterised by the production of fines, where fines were defined as any particles passing the $4.75 \mathrm{~mm}$ sieve after testing. So as to avoid issues with possible size effects $[5,6]$, each sample was prepared to have the same range of initial particle sizes, ranging between 4.75 and $19.6 \mathrm{~mm}$.

Tests were performed using a 300 x 300mm Prolab Direct Shear Machine (DSM) with a 1MPa capacity (Fig 1a). Tests were carried out with normal stresses ranging from $9 \mathrm{kPa}$ to $3.5 \mathrm{MPa}$. To achieve stresses greater than $1 \mathrm{MPa}$, concrete and steel inserts (Fig 1b) with a $167 \mathrm{~mm}$ circular sample space were manufactured, that could be inserted into the $300 \mathrm{~mm}$ shear boxes, reducing the sample area by about $75 \%$. For stresses less than 100 $\mathrm{kPa}$, the mass of the box and insert became significant, and hydraulic control of the DSM (Fig 1d) was unable to apply and maintain the normal stress to sufficient accuracy. So, for the 9 and $48 \mathrm{kPa}$ tests, a special lightweight top box was fabricated (Fig 1c) and the normal load was applied using deadweights (Fig 1 e, f).

Samples were carefully prepared by sieving the required fractions from bulk samples. A fraction mixture with roughly $1 / 4$ of each size was selected: $21 \% 4.75$ $6.7 \mathrm{~mm} ; 23 \% 6.7-9.5 \mathrm{~mm} ; 23 \% 9.5-13.2 \mathrm{~mm} ; 32 \% 13.2-$ $19 \mathrm{~mm}$. After several bench trials, a target mass was determined to allow samples to be prepared to the same consistent, loose initial density for each test: 1126 $\mathrm{kg} / \mathrm{m} 3$; corresponding to a relative density of $0 \%$.

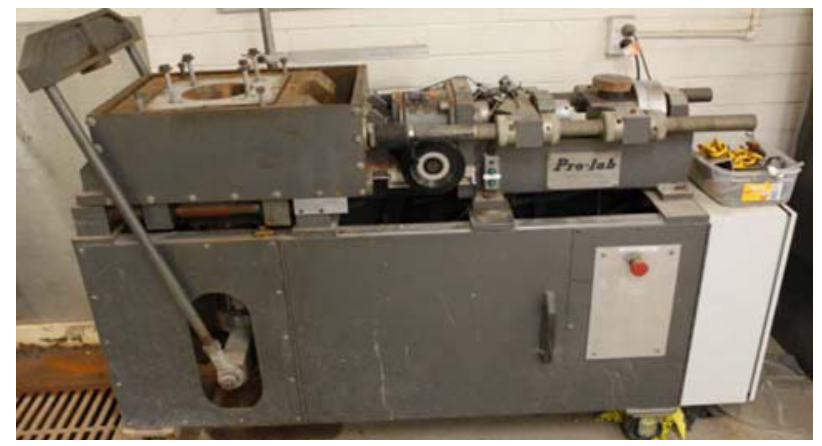

a) Prolab direct shear machine, with inserts installed

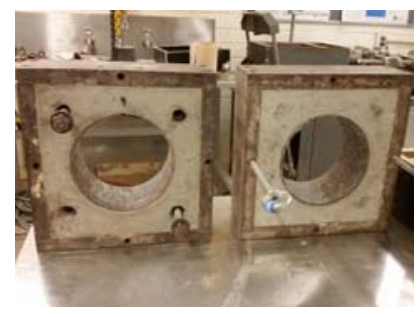

b) inserts for area reduction

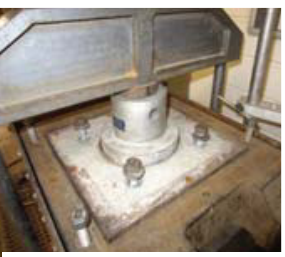

d) hydraulic loading

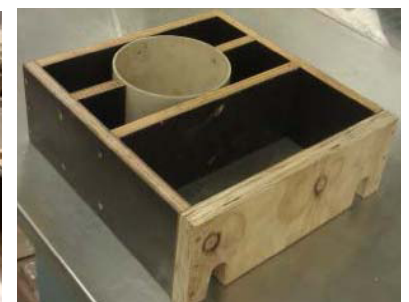

c) lightweight top box

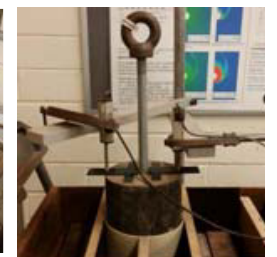

e) $9 \mathrm{kPa}$ loading

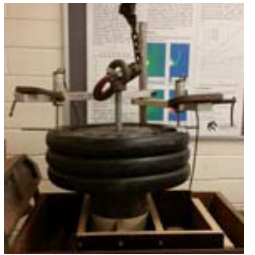

e) $48 \mathrm{kPa}$ loading
Fig. 1. Features of the testing arrangement.
Dense specimens were created by dry pluviation, in which the sample was "rained" by delivering it slowly through a $1 \mathrm{~m}$ long, $150 \mathrm{~mm}$ diameter PVC tube, fitted with a $19 \mathrm{~mm}$ grid mesh at half height. This resulted in the same consistent, dense initial density for each test of $1299 \mathrm{~kg} / \mathrm{m} 3$; corresponding to a relative density of $71 \%$.

Acknowledging that significant particle breakage may occur in the application of the normal compressive stress, even before the sample is sheared, particle breakage during shear was estimated as follows:

1. Prepare a new sample, apply compression, determine fines.

2. Prepare a new sample, apply compression, shear, determine fines.

3. Estimate fines due to shear as the difference between samples tested by compression and shear (2.), and compression only (1.).

Determination of fines after compression and/or shearing involved careful recovery of all the tested material and a sieve analysis. After testing under 3.5 $\mathrm{MPa}$, the compression of the siltstone was so substantial that the recovered sample was effectively a monolith. Before it could be sieved, it had to be broken up. This was achieved very carefully by gently teasing out crushed and recompacted material that had clearly been reconstituted by the test process, whilst not breaking down primary particles that had not been damaged.

\section{Results}

Figure 2 shows the shear stress/shear displacement data for low and high density tests, plotted in terms of the secant friction angle ( $\tan ^{-1}$ (shear stress/normal stress)). At low normal stresses, the shear strength of dense samples exceeds the shear strength of the loose samples, but with increasing normal stress, the difference reduces. For normal stresses of $250 \mathrm{kPa}$ or greater, there is no significant difference in the peak shear strength, although the shape of the shear strength response differs.

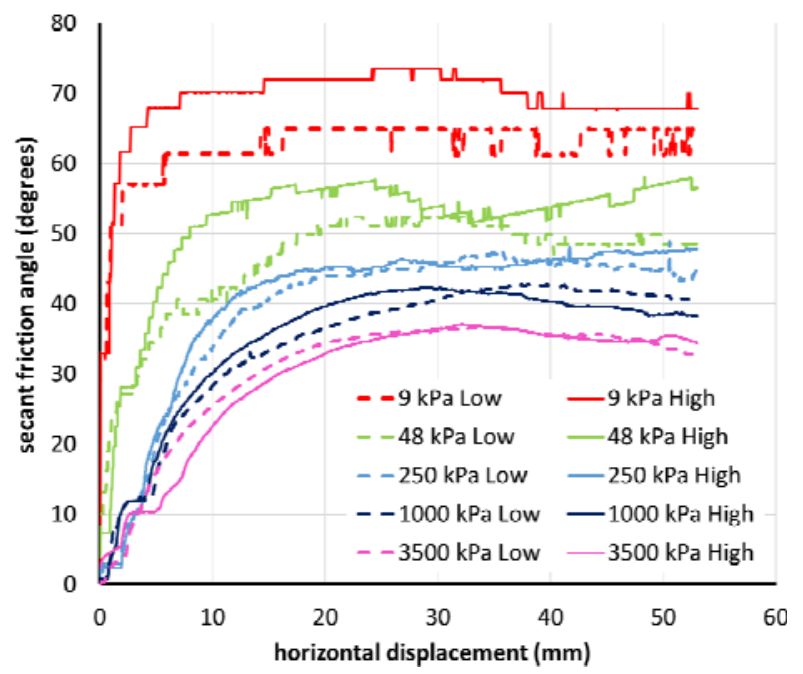

Fig. 2. Shear strength (secant friction angle) vs horizontal displacement for low density and high density tests. 
Figures $3 \mathrm{a}$ and $\mathrm{b}$ show the peak secant friction angle for the low and high density samples. The severe and rapid reduction in the peak strength with increasing stress on a linear scale in Fig 3a) is consistent with the general expectation of shear strength envelope nonlinearity. Whilst the non-linearity is strong for both the loose and dense samples, the friction angle, and its corresponding decrease with increasing normal stress, are greater for the denser samples.

However, by the time the normal stress reaches 250 $\mathrm{kPa}$, the peak friction angle is similar for loose and dense samples, and it remains so as the normal stress becomes very large. The convergence of the loose and dense peak friction angles, approaching a normal stress of $250 \mathrm{kPa}$, is clearly evident when the data is considered on a $\log$ normal stress scale in Fig 3b).

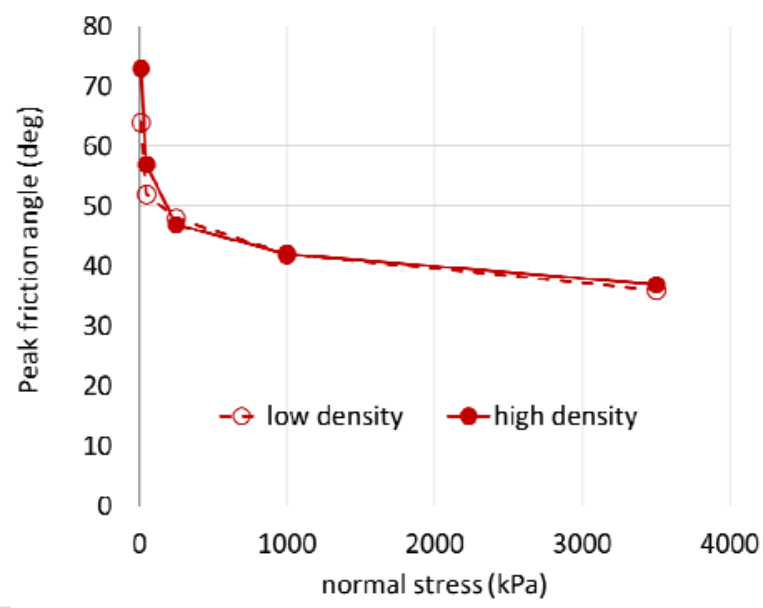

a) normal stress on a linear scale

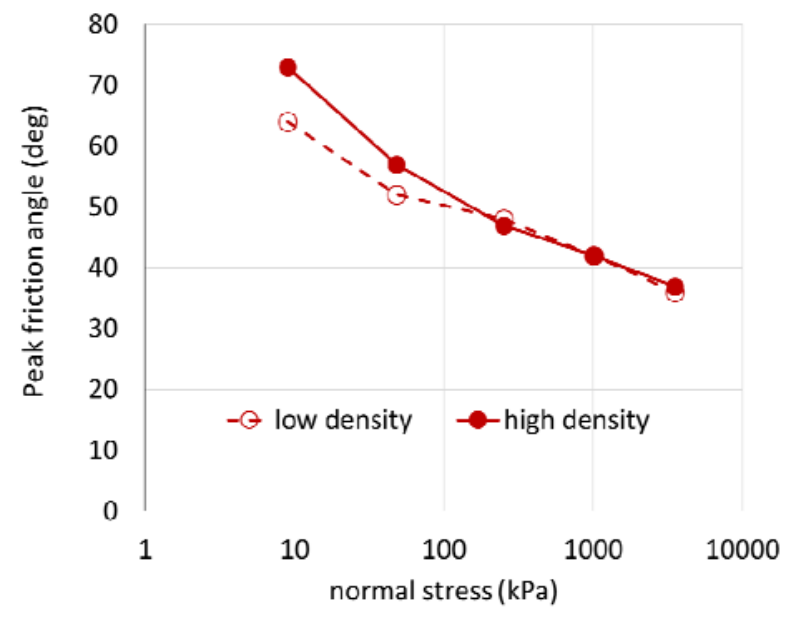

b) normal stress on a log scale

Fig. 3. Peak friction angle as a function of normal stress

Figure 4 shows the average vertical displacement (independent of top cap rotation) measured for all of the loose and dense sample tests. At very low normal stresses, the samples exhibit some compression before they begin to dilate; at higher normal stresses, they exhibit only compression. As expected, for the same normal stress, dilation is greater and compression is less in the denser samples than in the looser samples.

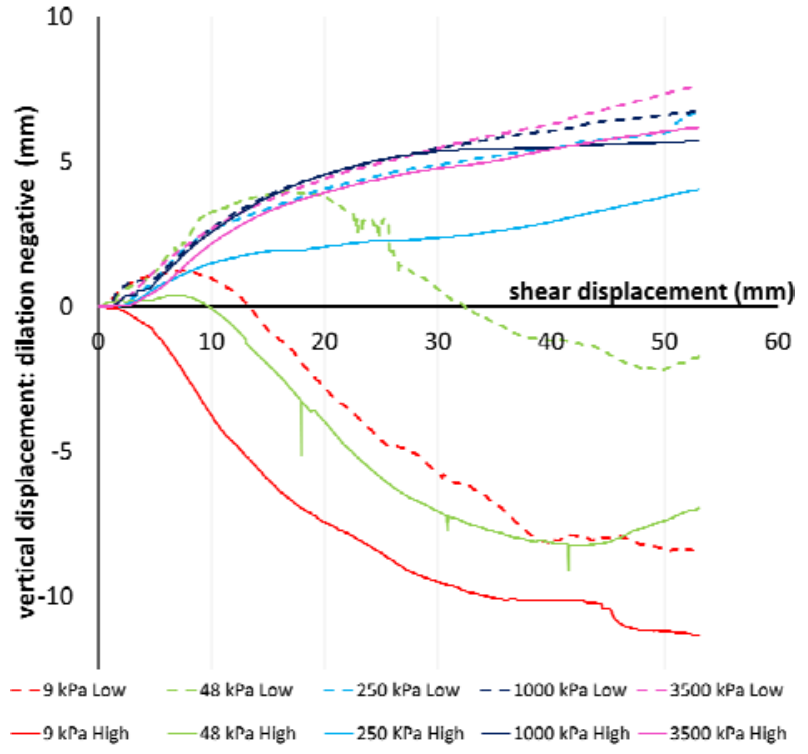

Fig. 4. Vertical displacement (dilation) vs shear displacement for loose and dense samples.

Figure 5 shows the effect of sample density on the extent of dilation/compression for different values of normal stress. The results suggest that dilation ceases at a normal stress of around $70 \mathrm{kPa}$ for the loose samples, but persists up to normal stresses of around $150 \mathrm{kPa}$ for denser samples. It would seem that in denser arrangements, the particle skeleton resists compression, and dilation is able to persist, beyond stresses that could force sample rearrangements by particle repacking, up to stresses which would instead cause particle breakage.

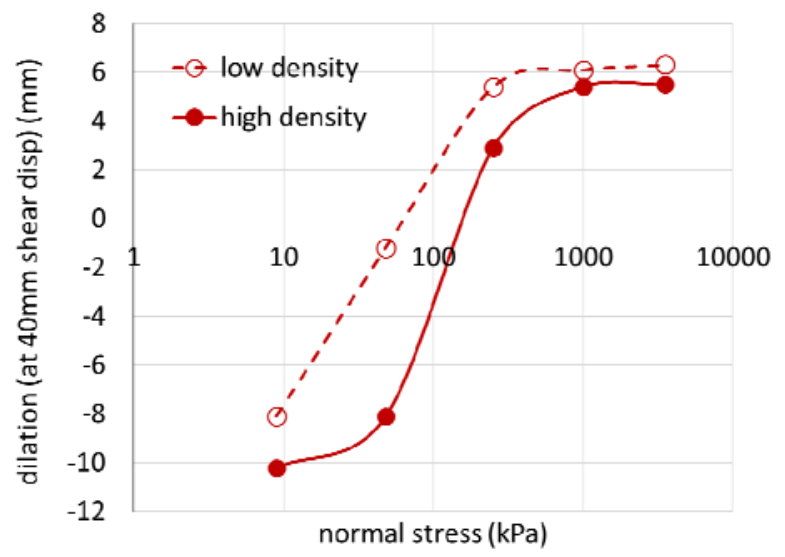

Fig. 5. Dilation (negative)/compression (positive) vs normal stress (values at $40 \mathrm{~mm}$ shear displacement).

To explore this idea further, it is necessary to consider the breakage behaviour as a function of the vertical stresses applied. Figure 6 shows the breakage due to compression (application of the normal stress), breakage due to compression and shearing, and by difference, the breakage due to shear alone.

Figure 6 suggests that particle breakage due to compression is relatively low until a normal stress of 250 $\mathrm{kPa}$ is reached. Thereafter, it continues to increase steadily as the $(\log )$ normal stress increases. 


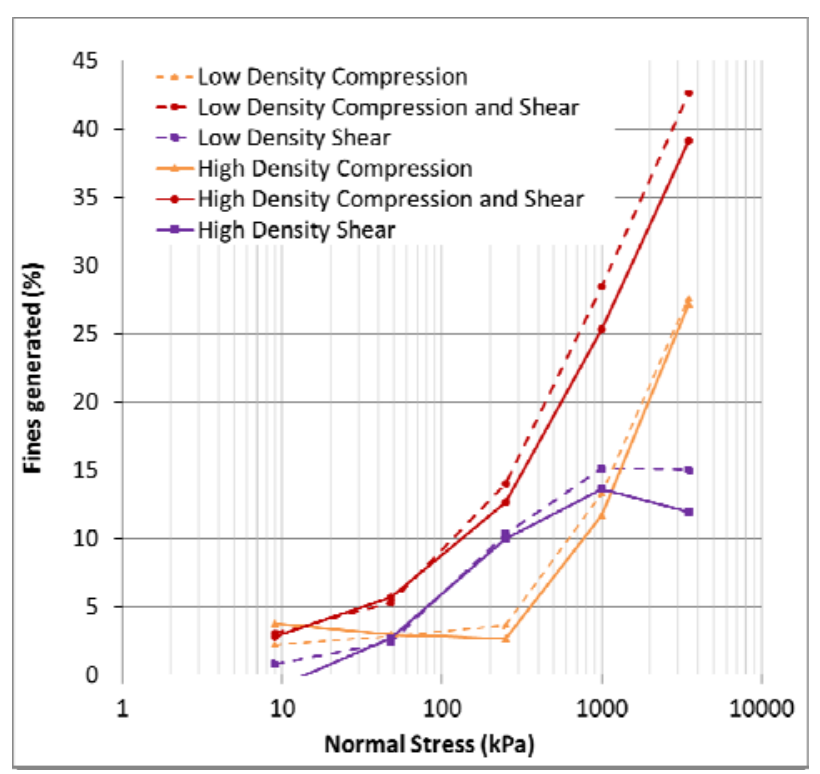

Fig. 6. Particle breakage due to compression, compression and shearing, and shearing in loose and dense samples.

Breakage due to shearing increases from the lowest of stresses, but increases more rapidly between normal stresses of 50 and $250 \mathrm{kPa}$, after which, the rate of breakage decreases, until reaching a maximum value at a normal stress of $1 \mathrm{MPa}$. At higher stresses, the high density sample actually experiences less breakage due to shear.

Other than for the high density sample at $9 \mathrm{kPa}$ (where the negative breakage value indicates an obvious error in very small masses), the loose samples tend to experience similar breakage to dense samples under low stresses, and more breakage than dense samples at higher stresses. This suggests that dense samples, despite being stiffer under low stresses (less able to compress due to particle repacking) are actually less prone to particle damage under high stresses. The reason for this is likely to be that denser packing leads to an increased number of particle contacts, allowing the particle point pressures to be reduced, hence causing less damage when loaded under a given high stress. The consequence of this, however, is that the loose samples, in experiencing greater damage, will attain a more efficient compressed structure and greater densification, causing them to become more like the dense samples under high normal stresses.

\section{Conclusions}

In light of the above observations, the following behavioural model is proposed for the significance of relative density for coarse granular materials with weak particles.

Under low normal stresses (ie, those insufficient to cause significant particle breakage) dense materials will record higher strengths than loose materials, because loose materials will tend to be repacked during shear to become denser, whereas already-dense materials will dilate to maximise their mobilised grain-sliding resistance.

Under high normal stresses (ie, those sufficient to cause significant particle breakage) loose materials will undergo greater particle crushing during normal load compression than dense materials, allowing them to attain denser structures which, consequently, result in them attaining similar strengths as denser materials when sheared under the same high stresses.

The authors would like to acknowledge the excellent work of Mr Jarrad Phelps in obtaining the experimental results, and the funding support of Australian Coal Research Limited.

\section{References}

1. P. Lade, J. Yamamuro, and P. Bopp, (1996) Significance of particle crushing in granular materials. Journal of Geotech. Eng. 122 pp 309-316.

2. Y. Nakata, Y. Kato, M. Hyodo, A.F.L. Hyde and H. Murata (2001) One-dimensional compression behaviour of uniformly graded sand related to single particle crushing strength. Soils and Foundations. 41, pp 39-51.

3. M. Bolton (1986). The strength and dilatancy of sands. Géotechnique 36, No. 1, pp 65-78

4. C. Ovalle, C. Dano and P.-Y.,Hicher (2013). Experimental data highlighting the role of surface fracture energy in quasi-static confined comminution. International Journal of Fracture, Vol. 182, pp 123-130.

5. W. Weibull (1939) A statistical theory of the strength of materials. Proceedings of Royal Swedish Institute of Engineering. Res. 151

6. S. Linero, C. Palma and R. Apablaza, (2007) Geotechnical characterization of waste material in very high dumps with large scale triaxial testing. Proceedings of International Symposium on Rock Slope Stability in Open Pit Mining and Civil Engineering, Perth, Australia,.pp 59-75 (ed.: Potvin, Australian Centre for Geomechanics).

7. C. Ovalle, C. Dano, P.-Y.,Hicher and M. Cisternas, (2015) Experimental framework for evaluating the mechanical behavior of dry and wet crushable granular materials based on the particle breakage ratio. Canadian Geotechnical Journal 52. pp 587598.

8. R. Marsal (1973) Mechanical properties of rockfill dams in Embankment dam engineering: Casagrande Volume., eds. R.C. Hirschfeld, , S.J. Poulos, Wiley, New York, pp 109-200.

9. T.M. Leps (1970) Review of shearing strength of Rockfill. Journal of Soil Mechanics and. Foundations Div. ASCE 96, pp1159-1170.

10. B. Indraratna, L. Wijewardena, and A. Balasubramaniam (1993) Large-scale triaxial testing of greywacke rockfill. Géotechnique 43, pp 539543 . 